\title{
Combustion of Methanol Droplets in Air-Diluent Environments with Reduced and Normal Gravity
}

\author{
Benjamin Shaw and Jingbin Wei \\ Department of Mechanical and Aerospace Engineering, University of California, Davis, CA 95616, USA \\ Correspondence should be addressed to Benjamin Shaw, bdshaw@ucdavis.edu
}

Received 14 July 2011; Accepted 29 February 2012

Academic Editor: Surbamanyam R. Gollahalli

Copyright ( 2012 B. Shaw and J. Wei. This is an open access article distributed under the Creative Commons Attribution License, which permits unrestricted use, distribution, and reproduction in any medium, provided the original work is properly cited.

Reduced and normal gravity combustion experiments were performed with fiber-supported methanol droplets with initial diameters in the $1 \mathrm{~mm}$ size range. Experiments were performed with air-diluent mixtures at about $0.101 \mathrm{MPa}$ and $298 \mathrm{~K}$, where carbon dioxide, helium, or xenon was separately used as the diluent gas. Results indicate that ambient gas transport properties play an important role in determining flammability and combustion behaviors including burning rates and radiant heat output histories of the droplets. Droplets would burn with significantly higher mole fractions of xenon than helium or carbon dioxide. In reduced gravity, droplets would burn steadily with a xenon mole fraction of 0.50 but would not burn steadily if helium or carbon dioxide mole fractions were 0.50 . Comparison with previous experimental data shows that ignitability and combustion characteristics of droplets are influenced by the fuel type and also the gravitational level. Burning rates were about $40 \%$ to $70 \%$ higher in normal gravity than in reduced gravity. Methanol droplets also had burning rates that were typically larger than 1propanol burning rates by about $20 \%$ in reduced gravity. In normal gravity, however, burning rate differences between the two fuels were significantly smaller.

\section{Introduction}

The combustion and gasification behaviors of droplets have been studied for decades for pragmatic and scientific reasons. For example, combustion of effervescent materials can produce burning particles under reduced-gravity conditions [1], which is relevant to practical aspects of spacecraft fire safety. Studies of droplets can also increase basic understanding of phenomena such as influences of diffusion, radiant heat transfer, and chemical kinetics on combustion of condensedphase materials.

The present research is focused upon studying influences of inert gases on ignition, combustion, and gasification of methanol droplets in normal gravity and reduced gravity. The droplets were initially, that is, before ignition, in the $1 \mathrm{~mm}$ size range and experiments were performed where air was progressively diluted with increasing levels of inert gas until combustion was no longer apparent. The inert gases were carbon dioxide, helium, and xenon. Helium and xenon are noble gases, leading to the same adiabatic (thermodynamic) flame temperatures for the same environmental compositions. However, differences in molecular masses between these species influence energy transport and transport of oxygen to droplet flame zones from variations in ordinary and Soret mass diffusion coefficients and thermal conductivities, leading to flame temperature, combustion, and flammability variations.

Previous results on droplet ignitability and gasification have been obtained with 1-propanol droplets [2] and n-heptane droplets [3] for both normal gravity and reduced gravity. However, the thermophysical properties and chemical kinetics of methanol are different than for 1propanol and $n$-heptane such that flame suppression and combustion characteristics for these fuels should be different. For example, burning rates and flame behaviors may be different because of differences in heat release rates and stoichiometries. Methanol droplets will also absorb water from the environment, which can influence burning rates and extinction characteristics [4-6]. In contrast, 1-propanol and $\mathrm{n}$-heptane droplets are not expected to absorb significant amounts of water during combustion. Because methanol and 1-propanol are both alcohol fuels, we compare the 
present methanol data with previous 1-propanol data. The 1-propanol data were compared with n-heptane data in [3].

An important dimensionless parameter in droplet combustion is the oxygen Lewis number, Le [7-9]. As Le decreases, flame temperatures increase because heat conduction from the flame becomes less efficient relative to transport of oxygen to the flame. The addition of an inert gas will change Le by altering properties such as the gas thermal conductivity, specific heat, density, and also effective oxygen diffusion coefficients $[10,11]$.

This Lewis number is the ratio of the mixture thermal diffusivity to the species diffusion coefficient of oxygen. Both quantities will change as the diluent level is varied. The mixture thermal diffusivity will be changed if the diluent alters the mixture thermal conductivity, density, or specific heat. The oxygen species diffusion coefficient will also be influenced by the diluent through variations in binary species diffusion coefficients as well as through variations in Soret transport effects, especially with xenon and helium, which have molar masses significantly different from oxygen molecules. For example, the addition of an inert component to air that has either a small molecular mass (e.g., helium) or a large molecular mass (e.g., sulfur hexafluoride or xenon) will alter oxygen transport to droplet flames via Soret diffusion and ordinary diffusion. In general, a species that is very light relative to oxygen (e.g., helium) will oppose transport of oxygen to droplet flames from Soret transport while a species that is very heavy relative to oxygen (e.g., xenon) will have the opposite effect. As has been noted elsewhere $[10,11]$ such effects can have significant influences on droplet behaviors. It is also worth noting that oxygen Lewis numbers and the effects of Soret transport have been found to be important in situations other than droplet combustion [12-18].

Other researchers have investigated inert gas substitution effects in reduced gravity droplet combustion. Yozgatligil et al. [19] and Park et al. [20] investigated combustion of ethanol droplets with helium, argon, or nitrogen as diluents. Bae and Avedisian [21] burned nonane droplets in oxygennitrogen-helium environments at one atm. The oxygen was fixed at $30 \%$ and the amounts of helium and nitrogen were varied. Hicks et al. [22, 23] burned methanol droplets in oxygen, nitrogen, and carbon dioxide environments at one atm and also at three atm. The oxygen was fixed at $21 \%$ and the relative amounts of nitrogen and carbon dioxide were varied. Nayagam et al. [24] report results from experiments on combustion of n-heptane droplets in oxygen-helium environments. The present experiments are different from these other efforts in that we progressively dilute air with a diluent gas, that is, the amount of diluent gas was increased between droplet combustion experiments, and we employ xenon as a diluent.

\section{Experimental Setup}

Experiments were conducted at the 2.2 Second Drop Tower at the NASA Glenn Research Center at Lewis Field in Cleveland, $\mathrm{OH}$. This drop tower provided gravitational levels of about $10^{-4}$ normal gravity [25]. Droplets were burned in a pressure chamber that was at about $0.101 \mathrm{MPa}$ (local atmospheric pressure) and $298 \mathrm{~K}$. Individual droplets with initial diameters that were typically about $1 \mathrm{~mm}$ were deployed onto a support fiber that had a diameter of about $125 \mu \mathrm{m}$. Droplet deployment was accomplished by pumping fuel through a hollow needle onto the fiber. Ignition was accomplished via two retractable hot wire loops. Igniter positions and currents were held constant.

Two video cameras were used to record droplet and flame histories. These cameras were oriented orthogonally to each other. The droplet-view camera was backlit and the flame-view camera was not backlit. The droplet-view camera provided close-up views of droplets while the flame-view camera provided information about flame sizes. Because of the backlighting, the droplet-view images generally did not show the flames.

An R-type thermocouple, which was used for gas-phase temperature measurements, was placed about $7 \mathrm{~mm}$ away from the support fiber. The thermocouple was included to enable recording of the appearance of flames, which were sometimes very weak and difficult or impossible to image, to be more clearly discerned than was possible with the video cameras. A radiometer that sensed wavelengths that included near-IR emission bands from water vapor and carbon dioxide was also employed. Further details about the apparatus are available elsewhere [2].

The video data were analyzed frame by frame using automated image-processing software. The images were analyzed to determine droplet sizes as a function of time. Uncertainties in length measurements are estimated to be about 5\% while uncertainties in burning-rate constants and gasification-rate constants are estimated to be about $10 \%$. The length uncertainty estimates are based upon the pixel sizes, the droplet sizes, and calibration of the video system by recording objects of known dimensions. The burningrate uncertainties are estimated to be about twice the length uncertainties because the burning rates are based upon measurements of droplet diameters, which are then squared. We estimate that these uncertainties correspond to about a 95\% confidence level.

\section{Results and Discussion}

The experiments were performed by progressively increasing (between experiments) the mole fraction of inert gas, $X_{D}$, in air until droplets could no longer be ignited where the inert gases added were helium, carbon dioxide, or xenon. Because of the relatively large parameter space and the limited number of drops that could be done, $X_{D}$ was typically increased in increments of $10 \%$, that is, $X_{D}$ values of $0 \%$, $10 \%, 20 \%$, and so forth were generally used. As the amount of diluent was increased, the flames became very dim, both in normal gravity as well as reduced gravity, and it was often not possible to determine whether ignition had actually occurred from the video records alone. Thermocouple and radiometer data provided definitive data in this regard.

Representative thermocouple temperature data are shown in Figures 1(a) and 1(b) for the situation where helium was used as a diluent in various amounts. Figure 1(a) 


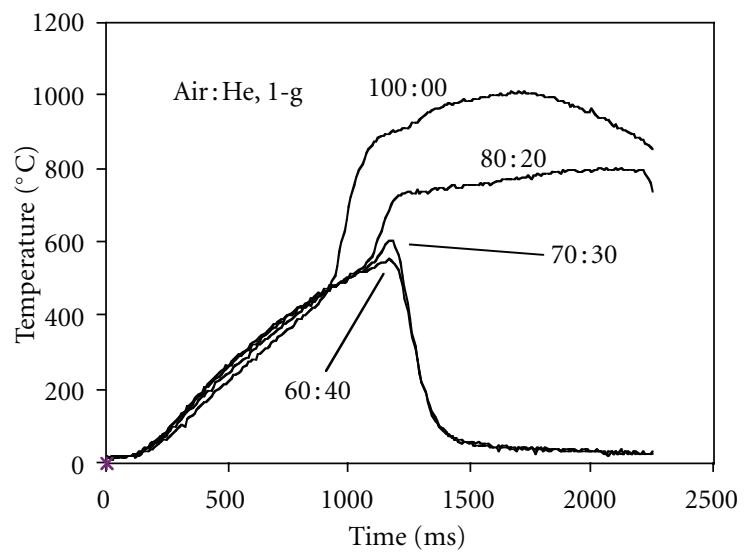

(a)

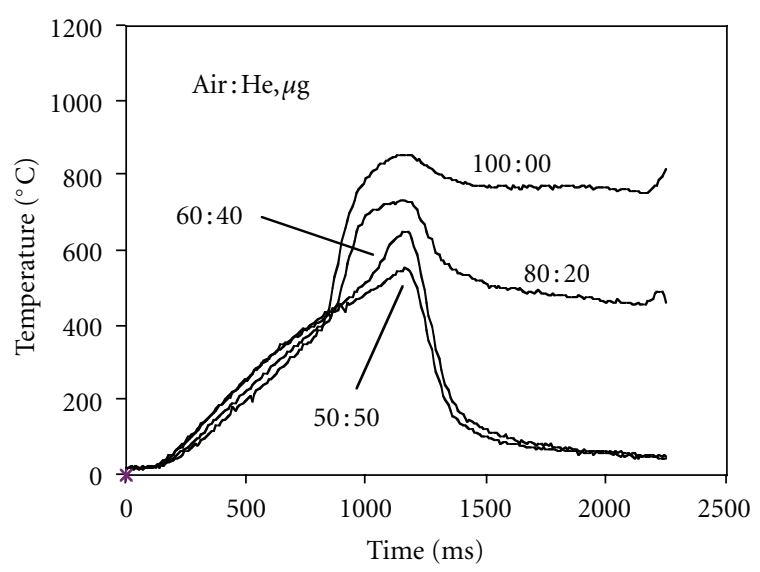

(b)

FIgURE 1: Thermocouple data for air : helium ambients: (a) normal gravity and (b) reduced gravity.

is for normal gravity and Figure 1(b) is for reduced gravity. The igniters are energized at about $200 \mathrm{~ms}$ and deenergized at about $1200 \mathrm{~ms}$, and their zero time corresponds to when the experiment package was dropped into reduced gravity. The amount of helium that corresponds to each curve in these figures is denoted in the figures, for example, the entry $80: 20$, where the first number (80) represents the molar percentage of air and the second number (20) the molar percentage of helium. This same notation is also used in other figures. In general, the thermocouple temperatures do not correspond to the flame temperature. This is because the thermocouple was typically not at the location of the peak temperature in the gas phase. The thermocouple measured gas temperatures near the peak temperature location, thus providing a clear indication of whether a gas phase flame was present or not.

As discussed in earlier studies with 1-propanol and nheptane droplets $[2,3]$, the thermocouple data can be used to identify different ignition and combustion regimes. The data in Figures 1(a) and 1(b) show three different cases that appear as the diluent level is varied: Case 1-negligible gas-phase heat release (as measured by the thermocouple); Case 2-appreciable gas-phase heat release that occurred only while the igniters were energized and near the droplet; Case 3-appreciable heat release that continued after the igniters were retracted, indicative of self-sustaining flames. For example, we may consider the thermocouple traces in Figure 1(b). The 50:50 data correspond to Case 1, that is, there was not any appreciable heat release detected by the thermocouple. For the 60:40 case, however, the sudden increase in the slope of the thermocouple data at about $800 \mathrm{~ms}$ indicated that droplet ignition occurred, but in this case the flame rapidly extinguished after the igniters were retracted (at a time of about $1200 \mathrm{~ms}$ ), which corresponds to Case 2. For the $80: 20$ data set, the gas-phase temperature remained high after retraction of the igniters, corresponding to self-sustaining gas-phase heat release (Case 3 ). The same general trends are evident in Figure 1(a). In this case, however, the different cases can appear at different values of diluent loadings, showing that the gravitational level influences the amount of diluent required to cause a droplet to burn, either with a heat source or without.

It is noted that Figures 1(a) and 1(b) do not show plots for all of the data sets that were obtained. Only selected data are shown to enable trends to be clearly illustrated. This is the case for other figures in this paper as well. For brevity, thermocouple data are also not shown for carbon dioxide and xenon. The same general trends were evident in these data in that the amount of diluent required to suppress ignition or steady combustion depends on the gravitational level as well as the type of diluent.

Figure 2 shows data obtained from the radiometer for the situation where helium was used as the diluent, where Figure 2(a) is for normal gravity and Figure 2(b) is for reduced gravity. In these figures, the time period from about $200 \mathrm{~ms}$ to about $1200 \mathrm{~ms}$ is when the igniters were energized. The igniters were deenergized and retracted at about $1200 \mathrm{~ms}$, which is when the radiometer readings begin to decrease. The radiometer sensed emissions from the igniter wires, which visibly glowed, emissions from hot regions of the support fiber, and also emissions from hot gases (primarily water vapor and carbon dioxide). The data in Figures 2(a) and 2(b) show the occurrence, or nonoccurrence, of sustained combustion. When droplets are not burning, the radiometer readings rapidly drop to essentially zero after the igniters are deenergized and retracted. However, when droplets are burning, the radiometer readings remain at several hundred counts after the igniters are deenergized and retracted. Both Figures 2(a) and 2(b) show that the highest radiant power levels occurred with pure air (no helium), where it is noted that the peak power levels are clipped for pure air at about 3400 counts because this was the maximum allowable value for the data acquisition system electronics.

In general, the radiometer readings are higher in reduced gravity than in normal gravity. This would be a result of the fact that buoyant flows in normal gravity would sweep hot gases away from the droplet zone, thus removing these gases from the field of view of the radiometer. These same 


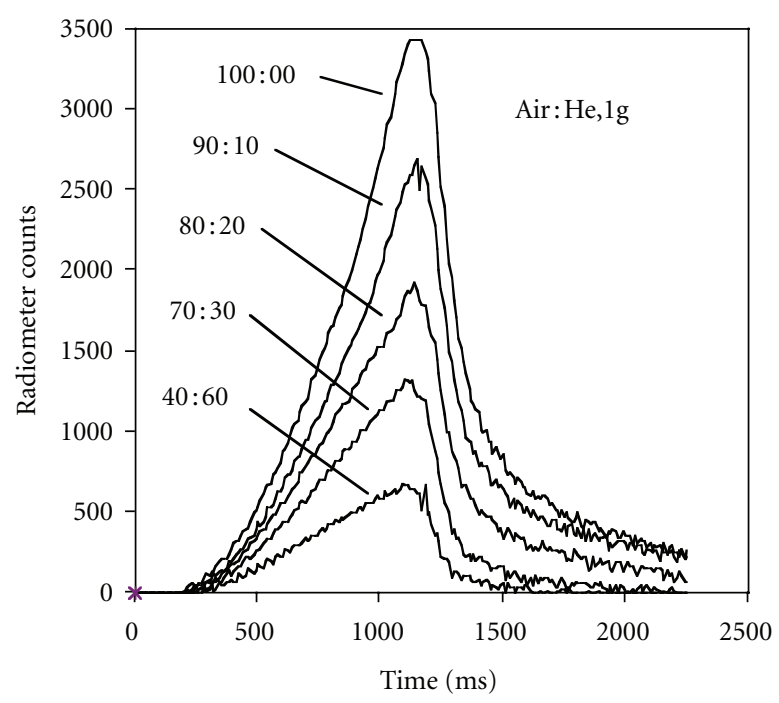

(a)

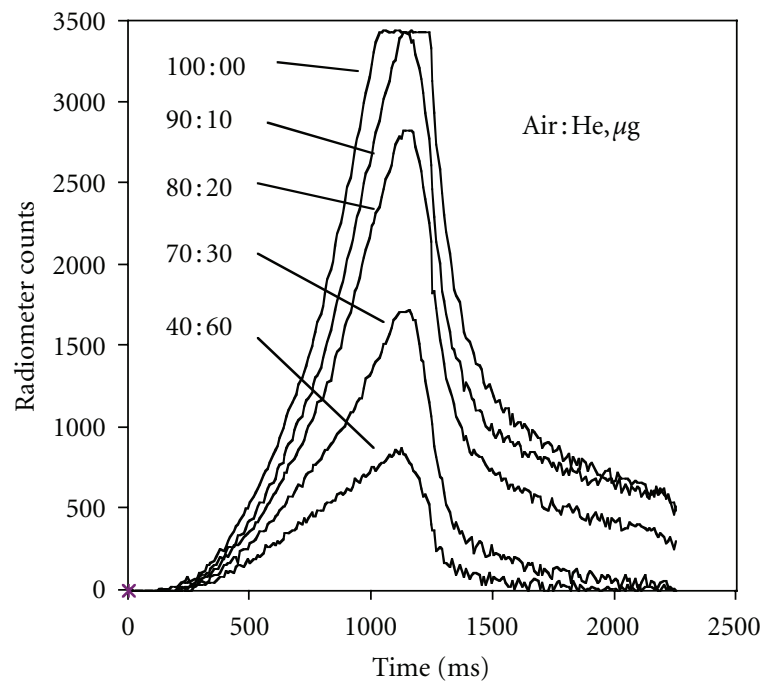

(b)

FIGURE 2: Radiometer data for air : helium ambients: (a) normal gravity and (b) reduced gravity.

convective flows would also cool the igniter electrodes, causing the electrodes to produce smaller levels of radiant emissions. In reduced gravity, the lack of significant buoyant flows would have led to slower cooling rates for gases and hot surfaces in the droplet zone, causing higher radiometer readings. The igniters also appeared to give off much larger amounts of radiant power than the fiber and also the hot gases around a droplet. This observation is based on the video records as well as the radiometer data, which show a sharp decrease in the radiometer levels after the igniter is deenergized and retracted from droplets that continued to burn.

As helium is added to the air, the radiant power levels generally drop in Figures 2(a) and 2(b). This occurs because the addition of helium will increase the gas thermal conductivity, which will cause hot gas zones (from flames or the igniter) and also the igniter wires and the support fiber to lose heat more rapidly to the environment via diffusion. The addition of helium will also dilute the oxygen, which will reduce the levels of strong gas-phase radiant emitters such as water vapor and carbon dioxide that might be produced, even in small amounts, during the time when the igniters are energized. Dilution of the oxygen level also leads to lower chemical heat release rates and thus lower radiant emissions.

The radiometer data were different for the cases where carbon dioxide and xenon were used as diluents in the sense that adding these diluents to the air could increase the radiant power sensed by the radiometer when small amounts of these species were added. For example, the data in Figure 3, which are for air: $\mathrm{CO}_{2}$ environments, show that going from $100: 00$ (pure air) to $90: 10\left(10 \% \mathrm{CO}_{2}\right)$ increases the radiant power levels in both the normal-gravity and reduced-gravity cases. The increases in the radiometer data in Figure 3 are likely related to changes in the gas thermal properties (e.g., thermal conductivity and specific heat) as well as the fact that hot carbon dioxide is a significant source of infrared radiation. As the level of carbon dioxide in the environment is increased further, the radiometer readings decrease because of oxygen dilution, that is, chemical heat release effects are diminished because of reduced oxygen levels, leading to cooler gases and surfaces in the droplet vicinity. Similar influences from xenon are expected, though it is noted that xenon is not expected to radiate strongly by itself. The presence of xenon increases radiant heat outputs through increases in the flame temperature that are caused by variations in transport properties. In particular, xenon enhances oxygen transport to the flame zone (via Soret transport) and reduces the gas thermal conductivity, both of which lead to increased flame temperatures. Eventually, though, increasing xenon levels will reduce flame temperatures because of oxygen dilution.

Table 1 presents data for the amount of diluent required to cause the onset of Case 1 (no detectable flames or heat release), Case 2 (i.e., where combustion occurs only while the igniters are energized and in the vicinity of the droplets), and Case 3 (where sustained combustion occurs after the igniters are retracted). The entries for 1-propanol are from previous experiments [2] while the methanol data points are from the present experiments. Because of the limited number of drop tower experiments that could be done, the present experiments did not precisely determine the $X_{D}$ values that lead to the onset of Case 1, Case 2, or Case 3. Rather, Table 1 shows data for the minimum $X_{D}$ values that were observed to cause each case to occur as $X_{D}$ was varied in discrete amounts. The data in Table 1 show that differences between the diluent gases can be appreciable.

Because helium and xenon are noble gases with nearly the same molar specific heats, the differences in droplet behaviors between these two gases are related to differences in transport properties. For example, helium has a higher thermal conductivity than xenon, and as such helium will promote flame extinction via heat loss effects. Because helium has a smaller molar mass than oxygen, Soret transport effects will also oppose transport of oxygen to flames if helium is present, further promoting flame extinction. 


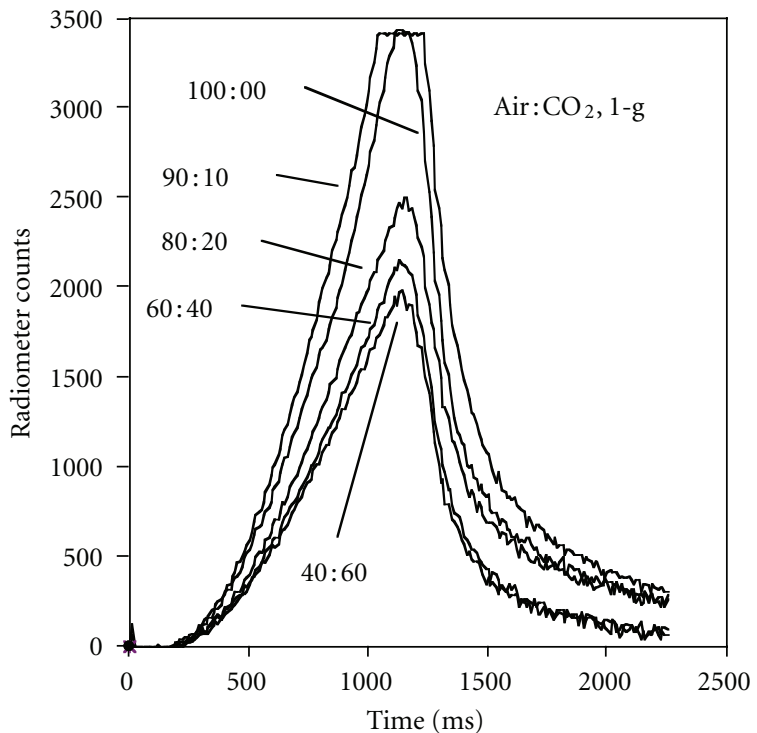

(a)

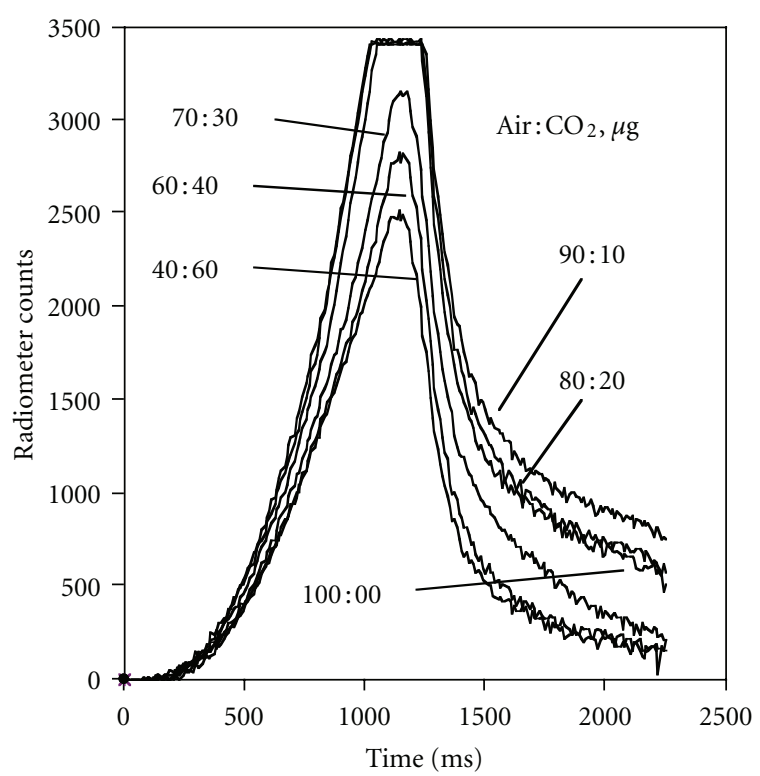

(b)

FIGURE 3: Radiometer data for air : $\mathrm{CO}_{2}$ ambients: (a) normal gravity and (b) reduced gravity.

TABLE 1: Diluent mole fractions required for the onset of Case 1 (negligible heat release), Case 2 (appreciable heat release that occurred only when the igniters were energized and near a droplet), or Case 3 (sustained combustion after the igniters were deenergized and retracted).

\begin{tabular}{lccccccc}
\hline Diluent & Fuel & $X_{D}$ Case $1 \mu \mathrm{g}$ & $X_{D}$ Case $2 \mu \mathrm{g}$ & $X_{D}$ Case $3 \mu \mathrm{g}$ & $X_{D}$ Case 1 1-g & $X_{D}$ Case 2 1-g & $X_{D}$ Case 3 1-g \\
\hline \multirow{2}{*}{$\mathrm{He}$} & 1-Propanol & 0.40 & 0.30 & 0.20 & 0.30 & - & 0.20 \\
& Methanol & 0.50 & 0.40 & 0.20 & 0.40 & 0.30 & 0.20 \\
$\mathrm{CO}_{2}$ & 1-Propanol & 0.50 & 0.40 & 0.20 & 0.40 & 0.30 & 0.10 \\
& Methanol & 0.50 & 0.40 & 0.20 & 0.30 & 0.20 & 0.50 \\
$\mathrm{Xe}$ & 1-Propanol & 0.90 & 0.80 & 0.50 & 0.60 & 0.70 & 0.40 \\
& Methanol & 0.85 & 0.80 & 0.50 & 0.80 & & 0.20 \\
\hline
\end{tabular}

Xenon will have the opposite influences because it has a larger molar mass and a lower thermal conductivity. The present experimental data show that these heat and mass transport factors influence the ignitability characteristics in normal gravity as well as reduced gravity. Table 1 also shows that the gravitational level can be important in determining the onset conditions for the three cases in that the $X_{D}$ values can be larger for reduced gravity than for normal gravity. The data in Table 1 also show that the onset conditions for the three cases can depend on the fuel, indicating that the fuel characteristics can be important in determining flammability characteristics.

Differences between fuel types on droplet ignitability are larger in normal gravity than in reduced gravity. This is likely because influences of buoyancy will be greater in normal gravity as the type and amount of diluent gas are varied, leading to greater variations in droplet heating rates. In reduced gravity, the differences between fuel types are largest when helium is used as a diluent (within the diluent mole fraction steps employed). This is likely caused by the higher volatility of methanol relative to 1-propanol as well as increased vapor diffusion rates when helium is used as a diluent.
Figures 4(a) and 4(b) show data on droplet size variations for droplets burning in air-helium environments in normal gravity and reduced gravity, respectively. These figures plot $d^{2} / d_{0}^{2}$ versus $t / d_{0}^{2}$, where $d$ is the instantaneous droplet diameter, $d_{0}$ is the initial droplet diameter, and $t$ is time. These data were used to evaluate average gasification rates, $K$, which are shown in Figures $5-7$. The $K$ values are defined to be the negative of the slope of a best-fit straight line that was fit to the $d^{2} / d_{0}^{2}$ versus $t / d_{0}^{2}$ data after the igniters were retracted and the $d^{2} / d_{0}^{2}$ versus $t / d_{0}^{2}$ data yielded an essentially straight line. The igniters were typically retracted at about $t / d_{0}^{2} \approx 1 \mathrm{~s} / \mathrm{mm}^{2}$. Figures $5-7$ show $K$ data for all fuels and ambient compositions as well as for normal and reduced gravity.

The data in Figure 4 show that there are periods where the $d^{2} / d_{0}^{2}$ versus $t / d_{0}^{2}$ plots are very linear and that the ambient composition affects the droplet history significantly. In normal gravity (Figure 4(a)) going from the 100:00 case to the $80: 20$ case reduced the burning rate somewhat after the igniters were retracted at about $1 \mathrm{~s} / \mathrm{mm}^{2}$. It is also apparent that the droplet in the $80: 20$ case extinguished at about $t / d_{0}^{2}=1.6 \mathrm{~s} / \mathrm{mm}^{2}$. This extinguishment was likely a 


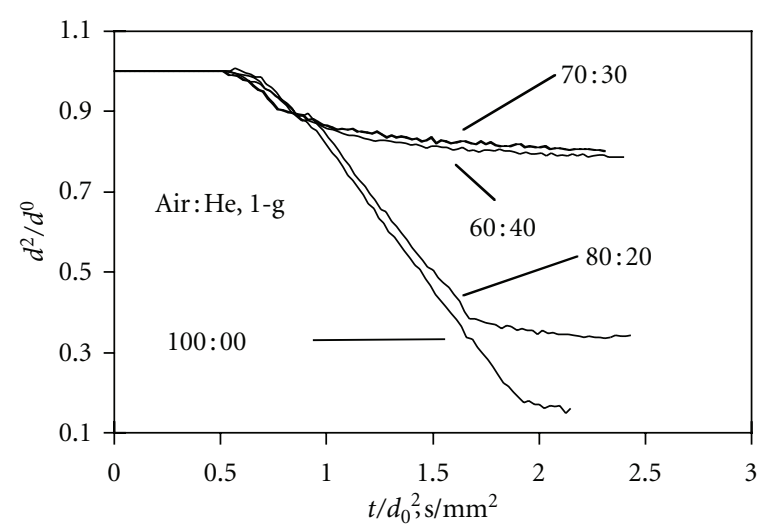

(a)

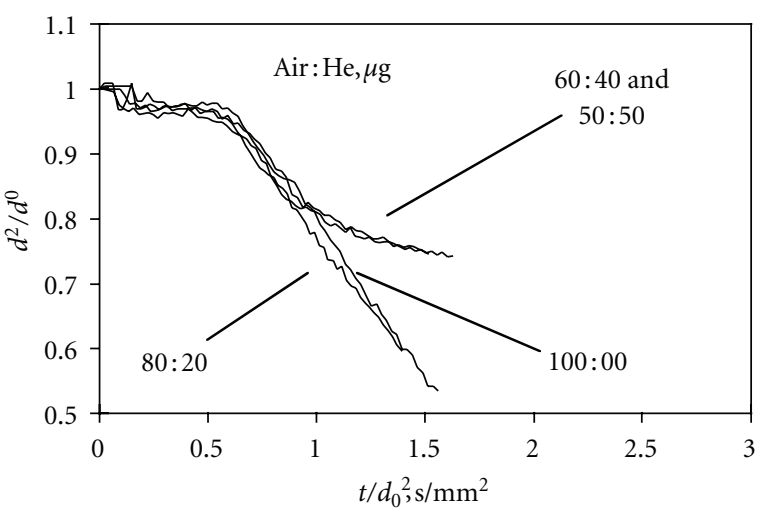

(b)

FIgURE 4: Droplet size data for air : helium ambients: (a) normal gravity and (b) reduced gravity.

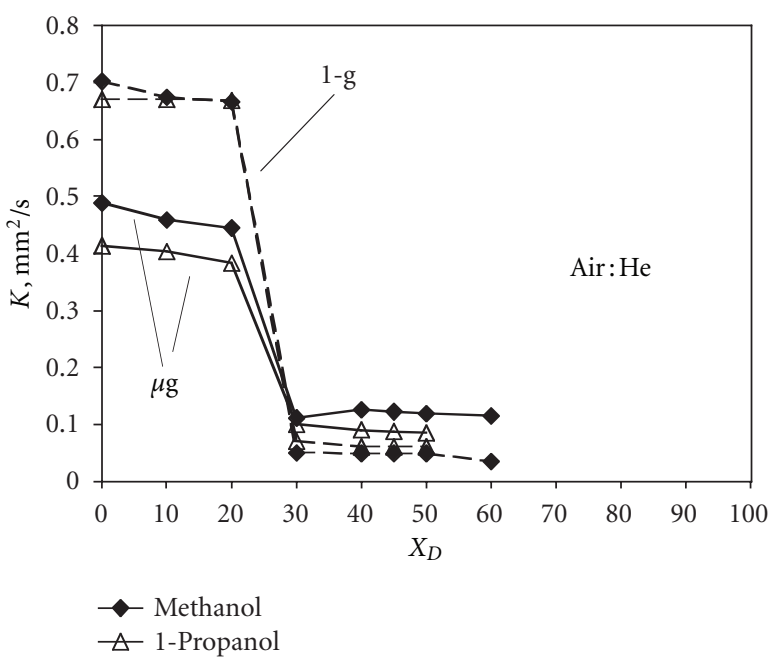

FIGURE 5: Gasification-rate data for air : helium ambients.

result of water absorption and subsequent gasification, as has been reasoned to occur with methanol droplet combustion [3-5]. These types of flame extinguishments are not apparent in the reduced gravity data (Figure 4(b)) because the droplets did not have sufficient time to accumulate water in the available reduced time $(2.2 \mathrm{~s})$. The data in Figures 4(a) and 4(b) also show that gasification rates become very small, corresponding to the absence of a flame after igniter retraction, when the diluent level is sufficiently high.

The data in Figures 5-7 show significant differences between the normal gravity and reduced gravity results. For the same environmental composition, $K$ values were larger in normal gravity when droplets were burning, which would be a consequence of buoyant convection. Interestingly, the $K$ values could be larger in reduced gravity than in normal gravity when the droplets were not burning. This is likely also a result of buoyant flows, but in this case the reduction of $K$ in normal gravity would be because the hot gases produced during the ignition sequence would have been swept away by buoyancy, leaving the droplet in contact

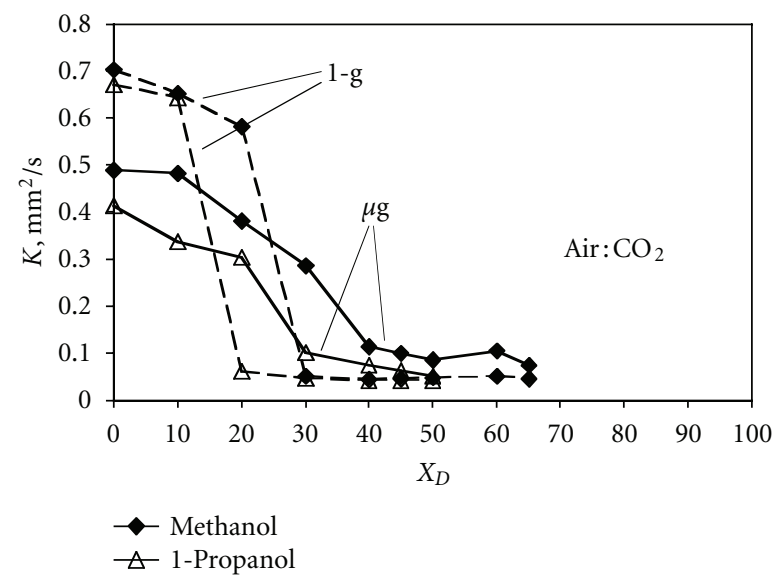

Figure 6: Gasification-rate data for air : $\mathrm{CO}_{2}$ ambients.

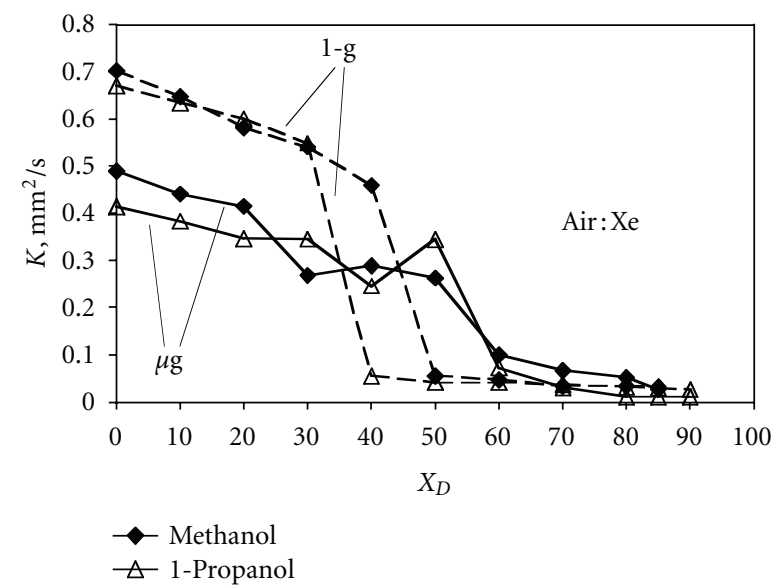

FIGURE 7: Gasification-rate data for air: xenon ambients.

with cool environmental gases. In reduced gravity, hot gases produced during the ignition sequence would remain in the droplet vicinity, promoting faster evaporation. 
Major differences between the fuels are that methanol has a higher volatility and methanol will also absorb significant amounts of water while it is burning, while water absorption effects are expected to be much less significant with 1propanol. The absorption of water can increase burning rates at early times because of the enthalpy of vaporization released into the liquid phase when water condenses on the droplet surface. As is evident in Figures $5-7$, the $K$ values for methanol and 1-propanol, when both are burning, are significantly more widely separated in reduced gravity than in normal gravity where the burning-rate data are strongly influenced by buoyancy effects. As a result, the reducedgravity results enable better observation of the effects of the fuel type. For example, methanol droplets typically burn faster than 1-propanol droplets in reduced gravity, which may be related to water absorption effects as well as the higher volatility of methanol.

The data in Figures 5-7 indicate that the identity of the inert gas can have important influences on gasification rates. For example, the data for air:Xe environments in reduced gravity (Figure 7 ) show a less abrupt transition in $K$ as $X_{D}$ is increased than is evident in the data for air: He and air: $\mathrm{CO}_{2}$ environments (Figures 5 and 6). These data also show that $K$ values are quite similar for the two fuels in normal gravity but that appreciable differences in $K$ are apparent in reduced gravity. In most cases, the $K$ values for methanol were larger than for 1-propanol under the same environmental conditions.

\section{Conclusions}

Methanol droplet combustion experiments with air-inert environments at $0.1 \mathrm{MPa}$ were conducted, where the inerts helium, xenon, and carbon dioxide were separately added to air in various amounts. In the experiments, the amount of inert gas in the environment was progressively increased until droplets could no longer be ignited. These experiments were performed in normal gravity as well as reduced gravity. The data obtained for methanol were compared with previous experimental results obtained with 1-propanol droplets.

Droplet ignitability depended on the gravitational level as well as the amount and type of inert gas in the environment. The fuel type also influenced ignitability. Helium and carbon dioxide typically required similar mole fractions in terms of inhibiting combustion, while combustion could be sustained with much larger xenon mole fractions. The large differences observed between helium, carbon dioxide, and xenon are likely a result of significant differences in transport properties between the gases. It is also worth noting that, on a mass fraction basis, smaller amounts of helium are required to inhibit combustion than carbon dioxide (and xenon).

It was also observed that radiometer readings and droplet gasification rates depended on the fuel type, the ambient gas composition, and the gravitational level. Typically, increasing the amount of inert gas decreased gasification rates while radiometer readings could increase or decrease as inert gas levels were increased. In addition, gasification rates and radiometer readings were typically larger in normal gravity than for corresponding reduced-gravity situations, which is a result of buoyancy influences.

Finally, it is noted that autoignition experiments could also be pursued, but we were not able to do this because of equipment limitations. Because autoignition experiments employ a high-temperature environment, different limits for ignitability would be obtained than what was observed in the present experiments, and these limits may not apply to the room-temperature environments investigated here.

\section{Acknowledgments}

The financial support of the National Aeronautics and Space Administration is gratefully acknowledged. The Technical Monitor was D. L. Dietrich.

\section{References}

[1] R. Friedman and H. D. Ross, "Combustion technology and fire safety for humancrew space missions," in Microgravity Combustion: Fire in Free Fall, H. D. Ross, Ed., Academic Press, New York, NY, USA, 2001.

[2] B. D. Shaw and J. B. Wei, "Propanol droplet flammability and combustion in air-diluent environments under normal and reduced gravity," Combustion Science and Technology, vol. 179, no. 6, pp. 1205-1223, 2007.

[3] J. B. Wei and B. D. Shaw, "Influence of gravity and ambient pressure on combustion and flammability of n-heptane and 1-propanol droplets in air-diluent environments," Combustion Science and Technology, vol. 183, no. 10, pp. 969-983, 2011.

[4] A. Lee and C. K. Law, "An experimental investigation on the vaporization and combustion of methanol and ethanol droplets," Combustion Science and Technology, vol. 86, no. 1-6, pp. 253-265, 1992.

[5] A. J. Marchese and F. L. Dryer, "The effect of liquid mass transport on the combustion and extinction of bicomponent droplets of methanol and water," Combustion and Flame, vol. 105, no. 1-2, pp. 104-122, 1996.

[6] J. Zhang and C. M. Megaridis, "Effects of the Lewis number of water vapor on the combustion and extinction of methanol drops," Combustion and Flame, vol. 112, no. 1-2, pp. 113-120, 1998.

[7] F. A. Williams, Combustion Theory: The Fundamental Theory of Chemically Reacting Flow Systems, Addison/Wesley, Redwood City, Calif, USA, 2nd edition, 1985.

[8] D. R. Kassoy and F. A. Williams, "Variable property effects on liquid droplet combustion," AIAA Journal, vol. 6, no. 10, pp. 1961-1965, 1968.

[9] C. K. Law, "Recent advances in droplet vaporization and combustion," Progress in Energy and Combustion Science, vol. 8, no. 3, pp. 171-201, 1982.

[10] I. Aharon and B. D. Shaw, "On the roles of thermal diffusion and distinct binary diffusion coefficients in modeling droplet flame locations in microgravity," Microgravity Science and Technology, vol. 10, no. 2, pp. 75-85, 1997.

[11] B. D. Shaw and V. Dee, "Influence of the gas phase inert on reduced-gravity combustion of decane/hexadecane droplets," Microgravity Science and Technology, vol. 17, no. 1, pp. 26-34, 2005.

[12] J. B. Greenberg and P. D. Ronney, "Analysis of Lewis number effects in flame spread," International Journal of Heat and Mass Transfer, vol. 36, no. 2, pp. 315-323, 1993. 
[13] Y. Zhang, P. D. Ronney, E. V. Roegner, and J. B. Greenberg, "Lewis number effects on flame spreading over thin solid fuels," Combustion and Flame, vol. 90, no. 1, pp. 71-83, 1992.

[14] S. Cheatham and M. Matalon, "Near-limit oscillations of spherical diffusion flames," AIAA Journal, vol. 34, no. 7, pp. 1403-1409, 1996.

[15] K. Mills and M. Matalon, "Extinction of Spherical Diffusion Flames in the Presence of Radiant Loss," Proceedings of the Combustion Institute, vol. 27, pp. 2535-2541, 1998.

[16] H. Bongers and L. P. H. De Goey, "The effect of simplified transport modeling on the burning velocity of laminar premixed flames," Combustion Science and Technology, vol. 175, no. 10, pp. 1915-1928, 2003.

[17] S. Palle and R. S. Miller, "Analysis of high-pressure hydrogen, methane, and heptane laminar diffusion flames: thermal diffusion factor modeling," Combustion and Flame, vol. 151, no. 4, pp. 581-600, 2007.

[18] M. Arias-Zugasti and D. E. Rosner, "Soret transport, unequal diffusivity, and dilution effects on laminar diffusion flame temperatures and positions," Combustion and Flame, vol. 153, no. 1-2, pp. 33-44, 2008.

[19] A. Yozgatligil, S. H. Park, M. Y. Choi, A. Kazakov, and F. L. Dryer, "Influence of oxygen concentration on the sooting behavior of ethanol droplet flames in microgravity conditions," Proceedings of the Combustion Institute, vol. 31, no. 2, pp. 2165-2173, 2007.

[20] S. H. Park, S. C. Choi, M. Y. Choi, and A. Yozgatligil, "New observations of isolated ethanol droplet flames in microgravity conditions," Combustion Science and Technology, vol. 180, no. 4, pp. 631-651, 2008.

[21] J. H. Bae and C. T. Avedisian, "Experimental study of the effect of helium/nitrogen concentration and initial droplet diameter on nonane droplet combustion with minimal convection," Proceedings of the Combustion Institute, vol. 31, no. 2, pp. 2157-2164, 2007.

[22] M. C. Hicks, V. Nayagam, and F. A. Williams, "Microgravity droplet combustion in $\mathrm{CO}_{2}$ enriched environments at elevated pressures," in Proceedings of the 5th U. S. National Combustion Meeting, Paper G18, San Diego, Calif, USA, March 2007.

[23] M. C. Hicks, V. Nayagam, and F. A. Williams, "Methanol droplet extinction in carbon dioxide enriched environments in microgravity," in Proceedings of the 6th U. S. NationalCombustion Meeting, Paper 31I4, Ann Arbor, Mich, USA, month year.

[24] V. Nayagam, J. B. Haggard, R. O. Colantonio et al., "Microgravity $\mathrm{n}$-heptane droplet combustion in oxygen-helium mixtures at atmospheric pressure," AIAA Journal, vol. 36, no. 8, pp. 1369-1378, 1998.

[25] J. Lekan, D. Gotti, A. J. Jenkins, J. C. Owens, and M. R. Johnston, "Users guide for the 2.2 second drop tower of the NASA Lewis Research Center," NASA Technical Memorandum 107090, 1996. 

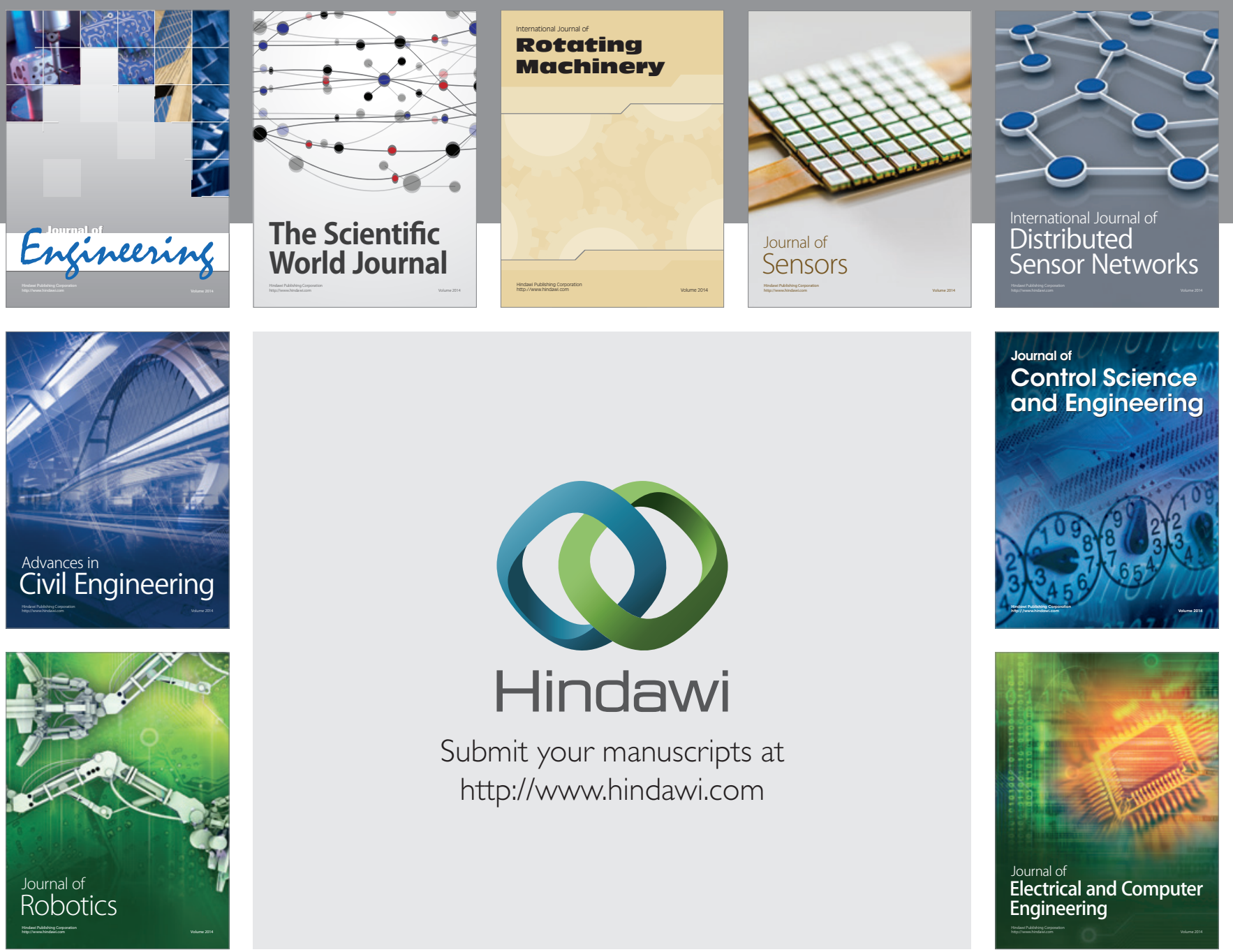

Submit your manuscripts at

http://www.hindawi.com
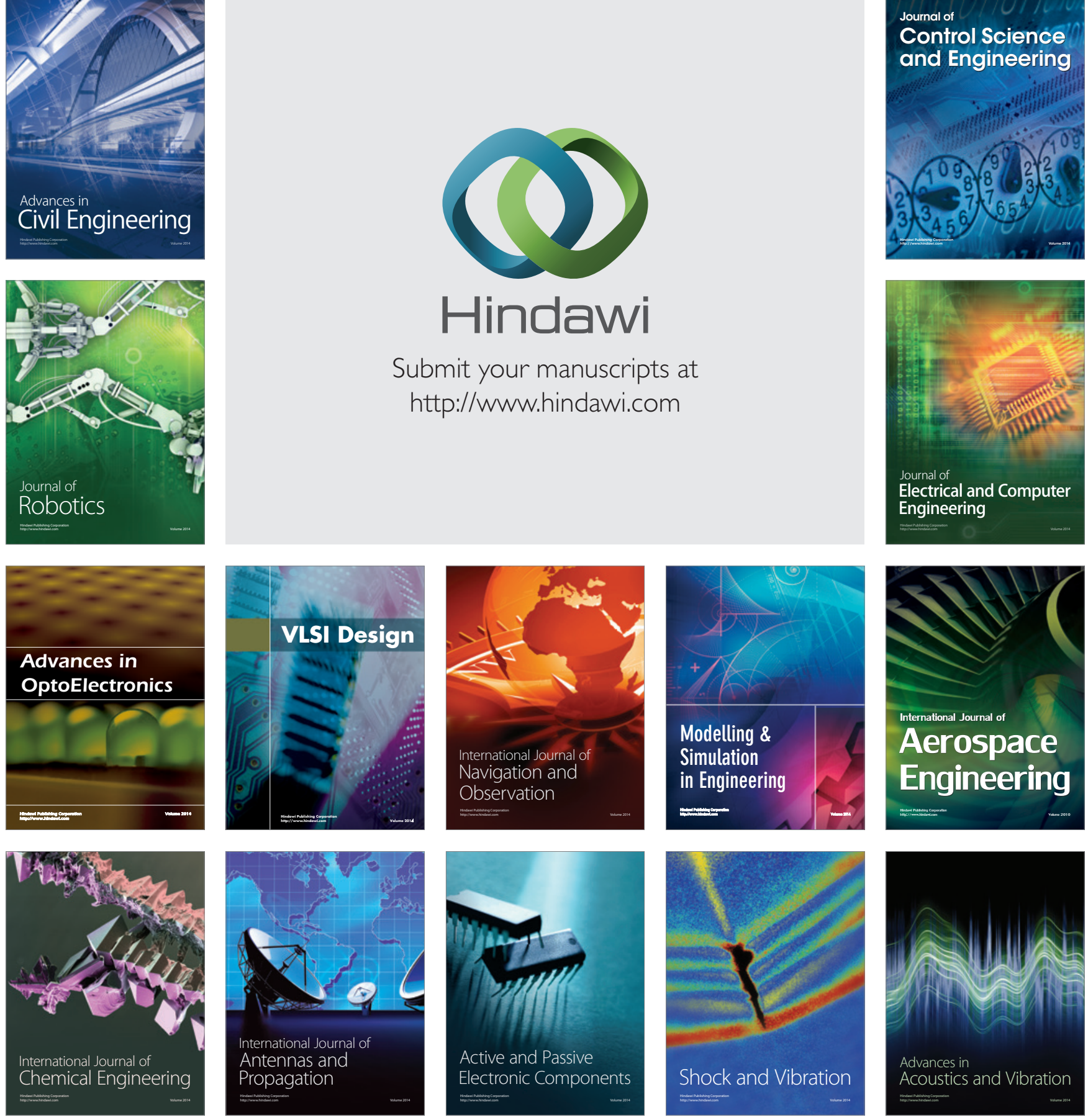